\title{
La Consulta Previa, Libre e Informada y la libre autodeterminación, autonomía y la territorialidad
}

The Free, Prior and Informed Consent in the face of the Free Self-Determination, Autonomy, and Territoriality

José Israel Herrera ${ }^{1}$

\section{Resumen}

La Consulta Previa, Libre e Informada (CPLI) se ha convertido desde la década de los años 80's del siglo pasado en un instrumento de protección de derechos que permite la resistencia ante situaciones asimétricas de poder. Ahora bien, esta CPLI, se ha introducido en diversos ordenamientos legales, políticas públicas o herramientas de gestión como una estrategia que beneficie a pueblos indígenas per se. Más sin embargo poco se ha generado sobre la discusión de sus orígenes, estrategias y elementos fundacionales. De aquí que este artículo genere un ejercicio reflexivo donde se reflexiona sobre los elementos filosóficos y teóricos fundacionales la Consulta Previa, Libre e Informada con la finalidad de profundizar e identificar los factores que contribuyan al desarrollo de esta herramienta especialmente en su relación con la libre autodeterminación, autonomía y territorialidad.

Palabras clave: Consulta Previa, Libre e Informada, Libre autodeterminación, Autonomía, Territorialidad

\section{Abstract}

The Free, Prior and Informed Consultation (FPIC) has since the 1980s become an instrument for the protection of rights that allows resistance to asymmetrical power situations. However, this FPIC has been introduced into various legal systems, public policies or management tools as a strategy that benefits indigenous peoples per se, but there has been little to generate about the discussion of its origins, strategies and founding elements. Nevertheless, so little has been said about their origins, their strategies and their basic elements. Hence this article generates a theoretical exercise where the prior, free and informed prior, free and informed consultation is reflected

Recibido: 6 de agosto de 2020 Aceptado: 15 de diciembre de 2020 Publicado: 1 de enero de 2021

${ }^{1}$ Profesor Investigador de Tiempo Completo del Centro de Investigaciones Jurídicas de la Universidad Autónoma de Campeche, México. Miembro del Sistema Nacional de Investigadores Nivel 1. Líneas de investigación: pluralismo jurídico, derechos humanos, minorías, derechos indígenas, antropología jurídica y DESCs. Correo electrónico: jiherrer@uacam.mx 
on the founding philosophical and theoretical elements in order to deepen and identify these elements that contribute to the development of this tool especially in its relationship with free self-determination, autonomy and territoriality. Keywords: Free Prior and Informed Consultation, Free Self-Determination, Autonomy, Territoriality

\section{Introducción}

La Consulta Previa, Libre e Informada (CPLI) a través de sus representantes o autoridades tradicionales, informada y de buena $\mathrm{fe}^{2}{ }^{2}$ es el más importante instrumento y mecanismo para garantizar el respeto y la protección de los derechos humanos individuales y colectivos de los pueblos indígenas, el cual dota de estructura y sustento ${ }^{3}$ al orden jurídico de mayor relevancia internacional con relación a los pueblos indígenas visto en el Convenio 169 de la Organización Internacional del Trabajo, que establece:

Es el derecho de participación de los pueblos indígenas en situaciones que impliquen una afectación a ellos y a sus derechos. Es un método de reconocimiento de los pueblos como autónomos y con libre determinación para darles la posibilidad de definir sus prioridades para desarrollarse. Es el derecho de los pueblos indígenas de elaborar las normas, buscando un acuerdo con ellos en los aspectos que los involucren (Comisión Nacional de los Derechos Humanos, 2016, p.10)

\footnotetext{
${ }^{2}$ Así se desprende la tesis aislada emitida por la Primera Sala de la Suprema Corte de Justicia de la Nación, de rubro: Comunidades y pueblos indígenas. todas las autoridades, en el ámbito de sus atribuciones, están obligadas a consultarlos, antes de adoptar cualquier acción o medida susceptible de afectar sus derechos e intereses. Consultable bajo los siguientes datos: Época: Décima Época; Registro: 2004170; Instancia: Primera Sala; Tipo de Tesis: Aislada; Fuente: Semanario Judicial de la Federación y su Gaceta Libro XXIII, Agosto de 2013, Tomo 1; Materia(s): Constitucional; (10a.); Página: 736.

${ }^{3}$ El derecho a la consulta previa es uno de los derechos humanos más importantes para los pueblos indígenas, ya que, por medio de éste, se les reafirma su autonomía y el derecho a la libre determinación al poder participar y decidir sobre los asuntos que les afectan o que los involucran. También es un derecho que promueve el diálogo intercultural, al buscar que se garantice la participación de los grupos indígenas en la toma de decisiones de proyectos que los puedan afectar, con el fin de proteger su integridad étnica y cultural. (Comisión Nacional de los Derechos Humanos)
} 


\section{La Consulta Previa, Libre e Informada y la libre determinación}

En principio se podría afirmar que la CPLI se trata del derecho que tienen los pueblos para formular una política propia y a establecer con autonomía las características de lo que atañe a su vida interna. Esta herramienta defiende el derecho a preservar la identidad cultural, social, económica y religiosa. Su pretensión no es la secesión sino el reconocimiento, respeto y participación dentro del estado del que forma parte. La libertad de determinación es polisémica cuando se refiere a sus manifestaciones de control sobre su territorio, recursos naturales, sistemas jurídicos, expresiones culturales, formas de organización social, elección de autoridades y representantes.

Es representativo que la Declaración de las Naciones Unidas sobre los derechos de los pueblos indígenas ${ }^{4}$ (DNUDPI) en sus artículos tercero y cuarto; el Pacto Internacional de derechos civiles y políticos en el artículo primero; y, el Pacto Internacional de derechos económicos, sociales y culturales, también en el artículo primero, se refieran al derecho a la libre determinación de los pueblos. ${ }^{5} \mathrm{La}$ prominencia que se le defiere a los diversos dentro de estos cuerpos normativos visibiliza un trato excepcional.

La CPLI, sólo existe bajo la tutela de un Estado democrático que reconozca los derechos culturales de los pueblos originarios y promueva y respete el ejercicio de la libre determinación bajo los parámetros de certidumbre establecidos para su eficaz resultado. Se puede entender por libre determinación la facultad de obedecer a la propia reflexión o determinación. En el derecho internacional implica el derecho de los pueblos indígenas a decidir sobre su propio futuro, por ejemplo, sobre su forma de gobierno e instituciones. (http://www.fondoindigena.org)

De lo anterior se colige la exigencia de los pueblos indígenas para establecer su condición política y perseguir libremente su desarrollo económico, social y cultural, en el marco del Estado y con relación al mismo. Lo anterior se encuentra claramente definido en la Declaración de las Naciones Unidas sobre los derechos de los pueblos indígenas en el que se expresa en sus artículos tres y cuatro:

Artículo 3. Los pueblos indígenas tienen derecho a la libre determinación. En virtud de ese derecho determinan libremente su

\footnotetext{
${ }^{4}$ El 13 de septiembre de 2007, la Asamblea General de la Organización de las Naciones Unidas aprobó, con 143 votos a favor, de un total de 192 países, la Declaración de las Naciones Unidas sobre los Derechos de los Pueblos Indígenas. México fue uno de los adherentes.

${ }^{5}$ Los Pactos Internacionales entraron en vigor en 1966; y la Declaración fue aprobada en el 2007.
} 
condición política y persiguen libremente su desarrollo económico, social y cultural.

Artículo 4. Los pueblos indígenas, en ejercicio de su derecho a

la libre determinación, tienen derecho a la autonomía o al autogobierno en las cuestiones relacionadas con sus asuntos internos y locales, así como a disponer de medios para financiar sus funciones autónomas. (Organización de las Naciones Unidas. 2007)

Desde aquí se acota la posibilidad de los pueblos indígenas de hacer extensiva esa libertad política para reconstruir un estadio precolonial fuera del marco del Estado actual al que pertenecen y, que, en México, se resguarda en el artículo segundo constitucional $^{6}$ y en su interpretación ${ }^{7}$ que sentencia que la nación es única e indivisible, y que el derecho de los pueblos indígenas a la libre determinación se ejercerá en un marco constitucional de autonomía que asegure la unidad nacional.

La reflexión inmediata anterior toma sentido al conocer la vastedad que sugiere el Pacto internacional de Derechos económicos, Sociales y Culturales en su artículo primero:

\footnotetext{
6 Artículo 2o. La Nación Mexicana es única e indivisible. La Nación tiene una composición pluricultural sustentada originalmente en sus pueblos indígenas que son aquellos que descienden de poblaciones que habitaban en el territorio actual del país al iniciarse la colonización y que conservan sus propias instituciones sociales, económicas, culturales y políticas, o parte de ellas. La conciencia de su identidad indígena deberá ser criterio fundamental para determinar a quiénes se aplican las disposiciones sobre pueblos indígenas. Son comunidades integrantes de un pueblo indígena, aquellas que formen una unidad social, económica y cultural, asentadas en un territorio y que reconocen autoridades propias de acuerdo con sus usos y costumbres. El derecho de los pueblos indígenas a la libre determinación se ejercerá en un marco constitucional de autonomía que asegure la unidad nacional. El reconocimiento de los pueblos y comunidades indígenas se hará en las constituciones y leyes de las entidades federativas, las que deberán tomar en cuenta, además de los principios generales establecidos en los párrafos anteriores de este artículo, criterios etnolingüísticos y de asentamiento físico.

${ }^{7}$ Libre determinación y autonomía de los pueblos y las comunidades indígenas. Interpretación del artículo 2o., apartado A, fracciones III y VII de la Constitución Política de los Estados Unidos Mexicanos. El citado precepto constitucional dispone que la nación mexicana es única e indivisible y tiene una composición pluricultural sustentada originalmente en sus pueblos indígenas, los cuales deben reconocerse en las constituciones y leyes de las entidades federativas; asimismo, de esta disposición constitucional se advierte que aquéllos gozan de libre determinación y autonomía para elegir: a) de acuerdo a sus normas, procedimientos y prácticas tradicionales a las autoridades o representantes para el ejercicio de sus formas de gobierno interno (fracción III); y, b) en los municipios con población indígena, representantes ante los ayuntamientos, lo cual, también debe reconocerse y regularse por las constituciones y leyes de las entidades federativas, con el propósito de fortalecer la participación y representación política conforme con sus tradiciones y normas internas (fracción VII). Por tanto, la observancia al artículo 2o., apartado A, fracciones III y VII, de la Constitución Política de los Estados Unidos Mexicanos, garantiza la libre determinación y autonomía de los pueblos y las comunidades indígenas. Controversia constitucional 70/2009. Municipio de Santiago Yaveo, Choapam, Estado de Oaxaca. 2 de junio de 2010. Cinco votos. Ponente: José Ramón Cossío Díaz. Secretarios: Laura Patricia Rojas Zamudio y Raúl Manuel Mejía Garza.
} 
1. Todos los pueblos tienen el derecho de libre determinación. En virtud de este derecho establecen libremente su condición política y proveen asimismo a su desarrollo económico, social y cultural.

2. Para el logro de sus fines, todos los pueblos pueden disponer libremente de sus riquezas y recursos naturales, sin perjuicio de las obligaciones que derivan de la cooperación económica internacional basada en el principio de beneficio recíproco, así como del derecho internacional. En ningún caso podrá privarse a un pueblo de sus propios medios de subsistencia. (Organización de las Naciones Unidas. 1977)

De esta manera se denota la lucha de los pueblos indígenas que la reivindicación histórica de la tierra ancestral es de vocación ontológica de los derechos humanos. El control sobre sobre sus propias decisiones presentes y futuras a partir del sanamiento de la deuda histórica, secuela del colonialismo. La lucha es procesual ${ }^{8}$; con una visión reparatoria que pretende habilitar gobiernos autónomos dentro una estructura jurídico-política neutralizadora que declara constitucionalmente la prevalencia de la unidad nacional.

Las realidades jurídicas y prácticas que se desprenden de esta conflagración se desarrollan organizando un cúmulo de interacciones y tensiones entre los pueblos indígenas y los estados de los que son parte geográfica. La autonomía y la territorialidad se levantan como los componentes principales de la libre determinación de los pueblos indígenas; y la Consulta Previa como instrumento para asegurar la materialización de la voluntad de los pueblos y comunidades indígenas en la defensa de sus culturas que dan origen a la composición pluricultural que nos sustentan como nación, como declara la Constitución Política de los Estados Unidos Mexicanos.

8 ...en el fin procesual el término o límite final del proceso suele situarse en el futuro; ello da lugar a dificultades insalvables (el futuro no existe, no puede actuar, etc.) que intentan ser resueltas mediante la introducción de una facultad ad hoc de representación de ese término futuro ... Pero el término "futuro" (el resultado, otras veces -cuando hay un proceso de causalidad eficiente-, el efecto) es el que ha de entenderse como determinante de la figura o concepto del propio proceso. Esto es lo que el análisis de los escolásticos expresaba metafísicamente al hablar del "influjo recíproco del efecto sobre la causa" -por la finalidad- y de la causa sobre el efecto -por la eficiencia. Tal "influjo" es absurdo, pues obliga a postular una mente influyente (humana o divina) ad hoc. De lo que se trata es de reconocer que el término final del proceso determina materialmente el mismo concepto del proceso... La única solución posible sólo podrá encontrarse regresando "más atrás" hasta interceptar esa llamada "representación del futuro". Si sustituimos la representación del futuro del proceso por la representación del término de otro proceso ya concluido que suponemos de la misma clase al de referencia, entonces podremos entender lógicamente el alcance de la idea de un fin procesual concreto. Este fin equivale a un destino, o si no, de una trayectoria que está cumpliéndose como análoga a otras trayectorias ya cumplidas. (Sierra, 2018) 
La Consulta Previa, Libre e Informada desde sus cimientos y simientes, tiene aparentes colisiones entre la normatividad internacional y la carta magna de México en la amplitud de alcances en relación a la libertad de la identidad cultural, derechos colectivos, autonomía, territorialidad, identificación de derechos humanos, pluriculturalidad, interculturalidad, pluralismo jurídico, positivización en las legislaciones estatales, protocolos de implementación y actuación, instituciones responsables, y evaluaciones de resultados, entre otros que iremos identificando.

Es necesario precisar que la autodeterminación no es sinónimo de secesión como se puede concluir del derecho internacional público en el que esta posibilidad es real para la creación de un nuevo Estado. La libre determinación como demanda de los pueblos indígenas se percibe como demanda de autonomía hacia el interior del Estado y respetuosa de sus fronteras. (Wilhelmi, 2009)

\section{La Consulta Previa, Libre e Informada y la autonomía}

La libre determinación y la autonomía se asocian como expresión jurídica y política en el reclamo de los pueblos indígenas para decidir sobre su presente y su futuro, pero conceptualmente se diferencian en que esta última es la forma concreta en que se ejerce la primera. La autonomía se ejerce en el interior de los pueblos y no se corrompe con la autonomía externa que se reserva al estado y que se expresa a través de la soberanía que es la potestad suprema para atender la res pública y la interacción con los pares internacionales.

A priori podemos racionalizar que no existe un modelo de autonomía estándar o único, que le sea aplicable a todos los pueblos; empero, siendo la libre determinación conditio sine qua non para el ejercicio de la autonomía, es menester prever que esa libertad fue gestionada o consensuada con el estado, estableciendo sus alcances. La autonomía implica per se la inmersión dentro fuerzas políticas; que además son cambiantes y que condicionan una gestión activa y continua para su adecuación. ${ }^{9}$

Concuerda lo expresado en el párrafo inmediato anterior con la carga utópica de búsqueda de libertad de los pueblos indígenas para su autodeterminación dentro de un marco estatal e internacional de cambios e intercambios sociales, económicos,

\footnotetext{
${ }^{9}$ Una referencia sobre esta discusión es Mouffe, que, en 2014, publica Agonística. Pensar el mundo politicamente. Mouffe hace una distinción entre "la política", que refiere al ordenamiento y organización de lo social, y "lo político”, que representa la dimensión antagonista de lo social en términos ontológicos. A partir de esta distinción, Mouffe muestra que el liberalismo niega la conflictividad del pluralismo social por medio de un consenso racional, cuya consecuencia es relegar la dimensión antagonista. Así mismo, este consenso repercute en la disolución de un "nosotros" y un "ellos", en cuanto que diferencia, como parte de la objetividad social. Mouffe, Chantal. (2018). Agonística. Pensar el mundo políticamente. Buenos Aires: Fondo de Cultura Económica.
} 
culturales, jurídicos y políticos. Búsqueda que guarda en contraposición, para sus detractores, sentimientos de escisión, ruptura, separatismo, desunión, aislacionismo, desintegración, fragmentación, desprecio y amenaza a la unidad nacional a guisa de balcanización.

La necesidad de un régimen autonómico para los pueblos indios ha sido recibida con recelo y escepticismo por quienes ven en la autonomía una amenaza para la unidad nacional y germen de separatismo. Hay también aquellos que se oponen a todo planteamiento autonómico para los pueblos indígenas o tribales por considerar que este podría derivar en un modelo de reservaciones que conduciría a los indígenas a la marginación y al aislamiento de la vida nacional.

Los defensores de la existencia de un régimen político autónomo para los indígenas tampoco cuentan con una visión unitaria acerca de cómo debe implementarse ni qué rasgos debería tener. Existen diversas posiciones al respecto: desde aquellas que defienden un modelo único para todos los pueblos... hasta las que pretenden construir la autonomía a partir de la experiencia histórica y de las características particulares de cada grupo indígena mexicano. (Zolla y Zolla Márquez, 2004)

La balcanización ${ }^{10}$ y la gobernabilidad amenazada surgen de inmediato en el imaginario social. "El término balcanización ha sido usado en los últimos años para referirse tanto al proceso de desintegración del estado yugoslavo, como, de manera más general, a la tendencia al desmantelamiento de las estructuras nacionales...” (Bazant de Saldaña, 1999, pp. 399-400).

Entendemos la balcanización como un proceso de fragmentación territorial de un espacio de cierta extensión (región o un espacio nacional), provocado por la presencia de conflictos o intereses divergentes entre los grupos sociales que ocupan diversas porciones de ese territorio antes unitario, y que inducen a la ruptura del consenso anterior, que había generado ese espacio más amplio.

Aplicado a un Estado-Nación lo anterior supone que por conflictos de diversa índole [...] se desvanece la valorización anterior de la unidad del Estado-Nación, induciendo a un repliegue de los diversos grupos o facciones en conflicto sobre sistemas de valores particulares y exclusivos del grupo mismo. Al no estar basados en los postulados que llevaron a la constitución de EstadoNación, surgen nuevas valorizaciones que excluyen las justificaciones del "estar-juntos", que emergieron del pensamiento de la Ilustración y se aplicaron en la formación de la mayor parte de

${ }^{10}$ Ha sido asociado con la idea de fragmentación nacional y con la emergencia de regionalismos y localismos. 
los Estados modernos, en los denominados países desarrollados.

(Bazant de Saldaña, 1999, pp. 399-400)

Vista así, la autonomía, como parte ejecutora del derecho a la libertad de determinación, se avizora compleja. Si no se es avezado en el manejo de los conceptos en lo individual, asociados estos, representan un galimatías geopolítico en lo internacional y en lo que cabe, en lo estadual.

\section{La Consulta Previa, Libre e Informada y la territorialidad}

No se trata de un elemento obvio sino de la mancuerna de la autonomía en cuanto la autodeterminación; y esta, a su vez de otros derechos colectivos que se pueden encontrar de manera primigenia con carácter vinculante para los Estados signantes en el Convenio número 169 de la OIT sobre pueblos indígenas y tribales:

La Declaración consta de 46 artículos en los que se establecen los estándares mínimos de respeto a los derechos de los pueblos indígenas, entre los que se incluyen la propiedad de sus tierras, los recursos naturales de sus territorios, la preservación de sus conocimientos tradicionales, la autodeterminación y la consulta previa (Organización Internacional del Trabajo, 2014, pp. 10-11)

La Consulta Previa como se desprende del 169 de la OIT es, además de derecho internacional vigente, instrumento mediante el cual se materializa la defensa de los demás derechos; valga el apunte en el entendido que la valoración constante de los otros derechos como la autodeterminación, que hemos estado abordando (así como abordaremos los demás), no representa un repliegue inconsciente a otro derecho colectivo, sino el acercamiento a la Consulta Previa a través de los demás y diferentes derechos a los que alimenta y defiende, derechos que en su corte estructural entrañan un derecho subjetivo pero no una figura material, fáctica, instrumental e integradora de la defensa general de los demás derechos como es el caso de la Consulta Previa.

Es así, que es importante fijar los elementos que primariamente conforman la autodeterminación, y que están constituidos por la autonomía y la territorialidad. Si bien no es una pretensión hacer un análisis exhaustivo de todos los elementos que conforman la demanda indígena, sí lo es el análisis de aquellos básicos que impactan su demanda al derecho humano de la Consulta Previa.

En la Teoría del Estado clásica, existen los elementos pueblo, territorio y soberanía como constitutivos, mientras que para los grupos indígenas esta se integra por pueblo, territorio y autonomía. Esta dicotomía constitutiva es relevante para ser analizada de forma paralela y en contraste. Considerar la precedencia de los pueblos 
indígenas a los Estados nacionales que ahora las comprenden resulta pertinente para observar la naturaleza reivindicativa que caracteriza la demanda indígena en general.

En primer lugar, encontramos que el territorio ${ }^{11}$ indígena es el hábitat donde se desarrolla la cultura de los pueblos indígenas con independencia de que exista o no continuidad territorial. Es uno de los derechos colectivos inherentes a la vida de los pueblos indígenas y clave en la delimitación y reconocimiento de sus derechos. Es el espacio geográfico que se encuentra bajo su influencia histórica, cultural, política y administrativa. Los pueblos indígenas cuentan con conocimientos ancestrales que están vinculados al territorio, y este, a sus rituales, creencias, lugares sacros, organización; y todo a la vez, con el aprovechamiento integral de los recursos naturales.

El desarrollo de la cultura de los vencedores sobre los vencidos genera nuevos entramados jurídicos y políticos vinculados al Estado. Existe inviabilidad política para acceder a un reconocimiento irrestricto en territorios que pese a la inobjetable preeminencia de los pueblos ancestrales hoy son ocupados o superpuestos con sujetos de derecho legalizados bajo las condiciones actuales.

Se considera que las personas ordenamos el mundo desde un centro, el egocentrismo, geocentrismo o etnocentrismo que es lo que da pie al sentido de lugar. El sentimiento de pertenencia y las identificaciones territoriales enlazan la geografía y la cultura. Los vínculos de dominio y las formas de apropiación territorial son temas que repuntan con esta demanda de los pueblos indígenas máxime el desdibujamiento virtual actual de las fronteras y territorios. (Avendaño, 2010, p. 13)

Desde la perspectiva geográfica, la territorialidad se define como la acción de significar un lugar y con ello, proteger, ratificar, defender, marcar, generar y alterar el territorio mediante hábitos, ritos, costumbres, prácticas y usos por un sujeto individual o colectivo. Los otros dos ejes conceptuales que enlazan a la territorialidad son los vínculos de dominio y de poder, y la apropiación vista como forma(s) de vivir y habitar un territorio (Avendaño, 2010, p. 15)

Lo territorial es una temática transdisciplinaria que en este caso establece una correlación entre geografía y cultura, o con más precisión para fines de esta investigación, entre territorio y derecho a la identidad cultural de los pueblos indígenas, que se acota a su vez en este trabajo a la Consulta Previa. ${ }^{12}$ La elaboración de un tejido fino conceptual permite recorrer y analizar desde los cimientos, las

\footnotetext{
${ }^{11}$ El artículo 13 del convenio 169 señala que la utilización del término "tierras" deberá incluir el concepto de territorios, es decir, la totalidad del hábitat que los pueblos interesados ocupan o utilizan de alguna manera.

12 Consulta previa, libre, informada, de buena fe y culturalmente adecuada.
} 
construcciones sociales denominadas derechos en la búsqueda de perfeccionar la reconciliación, en lo posible, a las demandas de reivindicación de los pueblos indígenas. La demanda de reconocimiento de las tierras ancestrales por parte de los pueblos originarios, conceptualmente se enfrenta al principio de integridad territorial recogido por la Carta de las Naciones Unidas y que mandata sobre los Estados miembros y que garantiza la preservación del territorio ante los pares y en general de la injerencia externa; en el caso de la demanda indígena la amenaza provendría del interior. La Carta de las Naciones Unidas lo estipula en el artículo 2 de la siguiente forma:

Para la realización de los Propósitos consignados en el Artículo 1, la Organización y sus Miembros procederán de acuerdo con los siguientes Principios: (...)

3. Los Miembros de la Organización arreglarán sus controversias internacionales por medios pacíficos de tal manera que no se pongan en peligro ni la paz y la seguridad internacional ni la justicia.

4. Los Miembros de la Organización, en sus relaciones internacionales, se abstendrán de recurrir a la amenaza o al uso de la fuerza contra la integridad territorial o la independencia política de cualquier Estado, o en cualquier otra forma incompatible con los Propósitos de las Naciones Unidas. (Organización de las Naciones Unidas. 1945)

La extrapolación de la amenaza desde el interior del Estado a partir de la salvaguarda que el principio de integridad territorial prevé para las amenazas desde el exterior, no resulta forzada si tomamos en cuenta que el espíritu de éste es la preservación del territorio desde la concepción del resguardo, protección, defensa y garantía. Pareciese enfrentarse el derecho a la integridad territorial ${ }^{13}$ (Carta de las Naciones Unidas. 1945) al derecho de la libre determinación de los pueblos, ${ }^{14}$ (Carta de las Naciones Unidas. 1945) pero no es así. Es claro que son los Estados los que pueden alegar el principio de integridad territorial contra sus pares internacionales en caso de injerencia u ocupación bajo el signo de promoción o apoyo a la libre determinación de un pueblo. No así, un Estado puede desconocer su obligación

\footnotetext{
13 Carta de las Naciones Unidas. Artículo 2 (4) Los Miembros de la Organización, en sus relaciones internacionales, se abstendrán de recurrir a la amenaza o al uso de la fuerza contra la integridad territorial o la independencia política de cualquier Estado, o en cualquier otra forma incompatible con los Propósitos de las Naciones Unidas.

14 Carta de las Naciones Unidas. Artículo 1 (2) Fomentar entre las naciones relaciones de amistad basadas en el respeto al principio de la igualdad de derechos y al de la libre determinación de los pueblos, y tomar otras medidas adecuadas para fortalecer la paz universal.
} 
jurídico-política de abastecer de las condiciones para que los pueblos ejerzan su derecho a la libre determinación arguyendo el principio de integridad territorial.

Interpretarlo de otra manera vaciaría de contenido la autodeterminación de los pueblos ante la figura de la integridad territorial. Dicho de otra forma, el ejercicio del derecho a la libre determinación de los pueblos en condiciones democráticas, pacíficas y sin injerencia de otro Estado no se enfrenta al principio de la integridad territorial de una Nación, sino que subsisten en diferentes esferas.

Desempacado de esta forma se pone de manifiesto que la Consulta Previa y la libre determinación son un derecho humano reconocido a los pueblos indígenas $\mathrm{u}$ originarios con fundamentos filosóficos y éticos; y que no depende de la voluntad del Estado bajo la jurisdicción se encuentra el pueblo concederla mucho menos denegarla.

Todos los poderes, órganos, instituciones y autoridades de Estados ratificantes del derecho de autodeterminación deben trabajar para facilitar tales mecanismos pacíficos y democráticos, respetando así el ejercicio de dicho derecho por parte de sus titulares: "todos los pueblos" bajo su jurisdicción. Una negativa a la facilitación, y aún más su obstaculización, serían violaciones graves de un derecho humano fundamental protegido al más alto nivel, y por tanto incumplirían obligaciones del Estado que se comprometió a su debido respeto ante la comunidad internacional y ante sus propios ciudadanos y ciudadanas. Ello entrañaría la responsabilidad del Estado y posiblemente también la de las instituciones implicadas en tales violaciones (Zayas, 2014)

\section{La Consulta Previa, Libre e Informada y la autodeterminación como derecho humano}

La reivindicación de los pueblos indígenas encuentra en el discurso de los derechos humanos la legitimidad y la fuerza que le dan la impronta actual. Sin embargo, no hay que soslayar la importancia de los principios de democracia y libertad como pilares adjuntos para la positivización del derecho a la consulta previa y la libre determinación.

Pudiera parecer factualmente conveniente la clasificación como derecho humano de la consulta previa y la libre determinación, cuando bien pudiera tratarse de otro tipo de derecho; no de menor importancia, sino diferente. La evaluación constante de su afirmación como derecho humano ${ }^{15}$ no es un acto de necedad sino de

\footnotetext{
15 Diversos autores han demostrado que existe una lógica de indivisibilidad e interdependencia en el derecho indígena, tal como existe en los derechos humanos en general. Esta lógica tiene que ver con la integralidad de los derechos indígenas, por lo que su desarticulación vaciaría de contenido a cada uno de los demás derechos.
} 
necesidad científica. Las discordancias en las opiniones agonistas y antagonistas obligan a la reflexión; y se intuye en la desaprensión sobre los derechos de las minorías respecto a la consulta previa y la libre determinación un desconcierto de fondo.

Ya establecido que la Consulta Previa y la libre determinación de los pueblos indígenas constituyen un derecho y no meramente una declaración política, se vuelve preciso despejar las dudas acerca de si se trata de un derecho humano

Las primeras dificultades que enfrentan la Consulta Previa y la autodeterminación en el discurso de los derechos humanos son su carácter colectivo y la titularidad que no recae en un ser humano. Y es que, a pesar de la masificación en su utilización, en realidad se hace referencia a un constructo moral-jurídico-político de contenido y contornos difusos. Por medio de conocer posturas encontradas que se refutan y que hacen falsables sus afirmaciones nos aproximaremos a la Consulta Previa y la autodeterminación para observarlos como derecho humano o como otra clase de derecho. Desde una perspectiva teórica la conceptualización de los derechos humanos deviene imprescindible.

La vulgarización de los derechos humanos en ocasiones no acierta en lo que Laporta afirma al decir: "Parece una obviedad que se olvida con cierta frecuencia que para hablar con fundamento de derechos humanos tenemos antes que saber hablar de derechos sin más" (Laporta, 1987, p. 3), es así, que se abordan los derechos subjetivos.

Sin quitar el foco de los derechos humanos sobre la cualidad de la consulta previa y la autodeterminación, nos tenemos que remitir, al menos someramente, a uno de los enfrentamientos más conspicuos de la ciencia jurídica como lo es el del iusnaturalismo con el iuspositivismo.

A priori podemos decir que tal desacuerdo se funda en la forma en que se observa el derecho teleológicamente y en la forma en que ambas corrientes establecen relaciones entre el derecho y la moral. Mientras el iusnaturalismo sostiene una relación intrínseca y justificatoria entre ellos, el iuspositivismo lo rechaza. Es decir, el primero observa al derecho como un contenido justo mientras que el segundo lo observa como un procedimiento formal.

Parece obvio que las connotaciones emotivas de la palabra "derecho" se deben a que los fenómenos jurídicos están estrechamente relacionados con valores morales,

Los derechos al territorio y los recursos naturales; a la identidad y la cultura; a la libre determinación; a la participación, la consulta y el consentimiento libres, previos e informados, así como el derecho indígena (o consuetudinario) son derechos básicos que deben ser entendidos como interdependientes e indivisibles. Es decir, un pueblo indígena requiere para su existencia que se respete su territorio, su derecho a la libre determinación, a la consulta y participación, a la identidad y cultura, y a una jurisdicción propia. Se trata en buena cuenta de un sistema integral e integrado, cuyo valor legal ya ha sido reconocido internacionalmente y que debe ser recogido como tal en las legislaciones particulares de los Estados. 
en especial el de justicia (la gente tiende a asumir actitudes emocionales toda vez que hay cuestiones morales en juego). (Nino, 2003, p. 16)

El iusnaturalismo prevalece en la cultura jurídica de Occidente hasta el siglo diecinueve en que surge el iuspositivismo y el historicismo ${ }^{16}$. El final del siglo diecinueve y la primera mitad del siglo veinte atestiguan la entronización del iuspositivismo. Este predominio del positivismo dejó una profunda impronta en la jurisprudencia y en los juristas. Nadie quiere en la actualidad ser tildado de iusnaturalista, pero en cambio no les repele ser denominados positivistas jurídicos o iuspositivistas. Cabe mencionar que ha renacido el iusnaturalismo de la mano de autores que quizá prefieran autodenominarse neo constitucionalistas:

... la Constitución no sólo está integrada por reglas, sino que también contiene principios, y su aplicación e interpretación debe realizarse no sólo por subsunción, sino que también mediante la ponderación. Autores como Comanducci, Robert Alexy o Ronald Dworkin sostienen que la Constitución, al estar integrada por principios, sirve como un puente entre el Derecho y la moral, y afirman que en el ámbito jurídico se deben respetar los principios morales que están reconocidos o institucionalizados en la Constitución. (Muñoz, 2014, p. 335)

El discurso contemporáneo sobre los derechos humanos está incardinado en esta corriente de pensamiento; y es que, si para el positivismo jurídico la negación del iusnaturalismo como respuesta a la validez del derecho constituyó su fortaleza, el derecho natural ${ }^{17}$ puede presumir la aceptación general de los derechos humanos

16 Historicismo es una corriente filosófica que le da gran importancia a la historia entre sus máximos representantes podemos señalar a Marx o Dilthey para el cual "todo cuanto el hombre es lo experimenta a través de la historia”. De esta se desprende el historicismo jurídico, escuela histórica entre los siglos XVIII y XIX en Alemania quienes estudiaron el derecho llegando a las conclusiones que este está condicionado al clima , la geografía, el gobierno imperante, la situación económica actual además de muchos aspectos relacionados pero en especial el espíritu del pueblo, el cual deviene de los pensamientos románticos de la época para los cuales que se transforma en una creencia ... los hombres en su vida llevan siempre a su lado un espíritu el cual les guía para bien o para el mal, al igual que el hombre entonces los pueblos también tienen un espíritu que los acompaña y que las manifestaciones de este son el derecho, entonces este derecho es previo a la norma que hace el legislador porque solo estos moldean el derecho ya preexistente. Para el historicismo, la forma más clara de manifestación del Derecho es a través de la costumbre, que es la primera y más auténtica fuente del Derecho. (Zamora, 2009)

17 Derecho natural es el orden intrínsecamente justo, que está por encima del positivo. Para los positivistas sólo existe el derecho que efectivamente se cumple o el vigente. Aunque limitada por el derecho las concepciones iusnaturalistas son de enorme variedad, pero todas coinciden en el dualismo normativo (derecho natural sobre positivo). Para algunas el fundamento del derecho natural radica en el poder (iusnaturalismo biológico), o en la divinidad, otros tienen la concepción sociológica del derecho natural, hay quienes lo refieren a los principios eternos e inmutables del ser humano (iusnaturalismo clásico) y el iusnaturalismo racionalista lo funda en la razón. Esta última busca el fundamento del derecho en valores objetivos ideales. (Máynez, 2000) 
cuyo basamento y fuente es el iusnaturalismo. Los derechos humanos constituyen de esta manera la transición o la evolución de los derechos naturales al derecho contemporáneo.

$\mathrm{Si}$ entendemos los derechos humanos como derechos morales se observa que fungen como una instancia crítica frente al positivismo jurídico, y, al mismo tiempo, aportan justificación al mismo iuspositivismo a guisa de parámetro de validez. Puede pensarse que un ordenamiento jurídico es superior moralmente a otro en la medida que conozca, respete y garantice los derechos humanos básicos.

Si se considera que los valores jurídicos de los derechos humanos de segunda generación (económicos, sociales y culturales) han sido cuestionados, se entiende por qué la validez de los denominados derechos de tercera generación, entre los que se encuentra el derecho de autodeterminación de los pueblos y la Consulta Previa, encuentran más comprometido su reconocimiento y aceptación. Hablamos de una categoría de derechos humanos que se halla en proceso de construcción, por lo que sus límites y alcances no se encuentran definidos, como se expresa a continuación:

(...) el catálogo de los derechos de la tercera generación está muy lejos de construir un elenco preciso y de contornos bien definidos. Se trata, más bien, de un marco de referencia, todavía in fieri, de las demandas actuales más acuciantes que afectan a los derechos y libertades de la persona. Incluso, el que, en ocasiones, se aluda a cuatro, en lugar de tres, generaciones de derechos contribuye a acentuar la indeterminación e incertidumbre de esta temática. Desde estos enfoques la tercera generación haría referencia a los derechos de los colectivos: trabajadores, mujeres, niños, ancianos, minusválidos, consumidores..., derechos que, por su contenido, parece más adecuado integrarlos en el ámbito de los derechos económicos, sociales y culturales que configuran la segunda generación. (Pérez Luño, 1998, p. 205)

Junto a este rasgo de incertidumbre que acompaña a la tercera generación de derechos humanos encontramos otras características que vuelven estos derechos especialmente susceptibles de ser criticados, particularmente su carácter colectivo. Se podría afirmar que los derechos de tercera generación son también derechos humanos sin que ello equivalga a una autorización para incluir en el catálogo cualquier aspiración humana individual o colectiva. El reconocimiento de nuevos derechos humanos y la positivización de estos no representan un desgaste, devaluación o minimización de los derechos humanos, se entiende que estos son generacionales y que el desarrollo de la sociedad y de la persona descubre nuevas oportunidades de igualdad, libertad y dignidad; justicia sin más. 
Encontramos que los derechos humanos son en esencia definidos como universales, absolutos e inalienables; lo que precisamos a continuación. Para la filosofía jurídica la universalidad es impugnada por su carácter ideal y abstracto que antagoniza con su pretensión generalizadora. Para la crítica política la universalidad resulta inicua por su intrínseca necesidad de proclamar ganadora a una tradición política de entre el universo de culturas. Y para la crítica jurídica resulta imposible la universalidad ya que reclama un marco social y económico que satisfaga todos los derechos humanos a nivel global para su cabal existencia (Pérez Luño, 1998, pág. 210)

La universalidad no puede quedar relegada a la esfera de los postulados ilusorios, reclama un esfuerzo constructivo tendente a su realización. Para ese empeño constructivista, la universalidad constituye una tarea a cumplir en ámbitos de debate policéntricos multinacionales y multiculturales. Si bien, para eludir el riesgo del relativismo, convendrá puntualizar que el coro plural de voces culturales no significa que todas las voces posean la misma intensidad y eco. Una de las voces cantantes de ese coro plural deberá ser, sin resquicio a dudas, la que corresponde al humanismo cosmopolita, que halló su expresión definida en el proyecto ilustrado de la modernidad (Pérez Luño, 1998, pp. 99-102)

Gracias a los debates contemporáneos sobre la universalidad de los derechos humanos podemos percibir su sentido y relevancia, y nos impide hipostasiar el concepto para convertirlo en un mero justificante político, jurídico o deontológico. La universalidad requiere de contornos firmes que le den significación más allá de la solemne retórica o el dogmatismo, como vemos a continuación, aunque no compartamos la misma opinión:

Los derechos humanos o son universales o no son. No son derechos humanos, podrán ser derechos de grupos, de entidades o de determinadas personas, pero no derechos que se atribuyan a la humanidad en su conjunto. La exigencia de universalidad, en definitiva, es una condición necesaria e indispensable para el reconocimiento de unos derechos inherentes a todos los seres humanos, más allá de cualquier exclusión y más allá de cualquier discriminación (Pérez Luño, 1998, pp. 212)

Ahora bien, aunado a esto cabe mencionar que se encuentra intrínsecamente vinculado al principio de progresividad de los derechos humanos lo que hace que la CPLI sea una herramienta que se encuentra formándose y ampliándose día a día conminando a una incorporación de los avances dados en instituciones e 
instrumentos vinculantes. La CPLI requiere de la toma de medidas a corto, mediano y largo plazo, pero procediendo lo más expedita y eficazmente posible.

En cuanto a la absolutividad de los derechos humanos se indica que vencen en todo caso a otras pretensiones; su característica común es que son considerados infranqueables y se alzan como un triunfo del individuo sobre las mayorías, y constituyen a la vez un límite al poder político, quienes no pueden legítimamente privar de sus derechos a los poseedores de este derecho subjetivo. El límite que constituyen no puede ser vulnerado en ningún caso, de manera que los derechos no pueden ser vencidos por circunstancia alguna o consideración moral. (Gálvez, 2014, pág. 4)

Constantemente el concepto de absolutividad de los derechos humanos también denominado supremacía se ve amenazado cuando colisionan dos derechos humanos; resulta claro que bajo esa etiqueta de omnímodo no pueden pervivir ambos por lo que uno dejaría de ser imperioso para el caso concreto. Y más aún, la realidad desmiente el carácter absoluto de los derechos humanos puesto que el orden jurídico positivo, la jurisprudencia vigente, y la propia Constitución les reconoce límites. ${ }^{18}$

Estos límites no se "crean" únicamente por la necesidad de conjugar el ejercicio de diversos derechos, sino por la voluntad constitucional de preservar determinados intereses que no son necesariamente derechos fundamentales. La inexistencia de derechos ilimitados se ha convertido en un tópico en materia de derechos humanos (Luque, 1993)

Presentan un valor absoluto sólo aquellos derechos que no entran en concurrencia o que no son derrotables por otros derechos sean naturales, vigentes o positivos como en el caso de la esclavitud y la tortura. Sin embargo, aún a este nivel, la discusión continua ante determinados supuestos como es el caso del ticking bomb scenario $^{19}$. Criticado por su carácter hipotético, emocional y poco probable, aun así, no deja de ser un importante ejercicio de falsabilidad. ${ }^{20}$

\footnotetext{
18 Artículo segundo, párrafo cuarto, de la Constitución Política de los Estados Unidos Mexicanos: El derecho de los pueblos indígenas a la libre determinación se ejercerá en un marco constitucional de autonomía que asegure la unidad nacional.(..)

19 (...) un terrorista que acaba de ser capturado confiesa que ha puesto una bomba en algún lugar (o que conoce su ubicación), la cual estallará de modo inminente y matará a cientos, miles, o, incluso, millones de personas. Por tanto, tal escenario tiene tres elementos: primero, la vida de muchos civiles inocentes está en peligro; segundo, la catástrofe es inminente; y, por último, un terrorista que ha sido capturado conoce información que podría evitar que dicho desastre ocurra. Ante dicha situación, pues, ¿tal sujeto puede ser torturado? Así, el debate sobre esta cuestión parte de una premisa que, al menos en teoría, todo el mundo acepta, a saber, la tortura es una práctica tipificada como delito (Anglí, 2010, pág. 11)

${ }^{20}$ Una vez roto el carácter absoluto de una norma bajo una justificación moral, intelectual o legal significa que no se basa en un principio moral absoluto.
} 
En el caso de la inalienabilidad ${ }^{21}$ de los derechos humanos se alude a la imposibilidad de que los titulares renuncien a los mismos. Los derechos humanos están adscritos al individuo y no dependen de su voluntad de aceptarlos o negarlos. Aún más, podríamos distinguir entre la titularidad y el ejercicio pues son independientes al grado de poder renunciar al ejercicio, pero no abdicar a la titularidad. ${ }^{22}$

\section{La Consulta Previa y los escenarios de negociación}

La Consulta Previa es el instrumento más importante de justiciabilidad de los pueblos y comunidades originarias ${ }^{23}$ para hacer valer sus derechos vinculados a su reconocimiento, libre determinación, salvaguarda de su cultura y participación política. Damos por sentado que la Consulta Previa es un derecho humano que tiene sus raíces y desarrollo en los sistemas políticos democráticos y que por ende debe estar estructurado en cuanto los fundamentos de este mismo. De hecho, el tipo de deliberación que ha desarrollado la CPLI ha sido en su construcción normativa, doctrinal e institucional muy cercana a la democracia deliberativa. Es así, que si a la Consulta Previa la desvinculásemos de un ejercicio deliberativo acorde a la democracia participativa resultaría en un cuestionario magnificado sin sentido.

La desaprensión de la Consulta Previa en su ejercicio después de tres décadas, a pesar de representar uno de los triunfos más importante de los derechos humanos a nivel internacional en relación a los pueblos indígenas, sugiere errores de fondo en la estructuración de este valioso instrumento; la misma nomenclatura pudiese ser desafortunada al no hacer referencia a principios o valores que sugieran la búsqueda del bien común como fin último, o la deliberación como elemento democrático de construcción de consensos $\mathrm{o}$, de ideales jurisprudenciales como argumento teleológico.

La Consulta Previa está sujeta a tensiones como las relativas a la pretensión de imponer los intereses grupales sobre los individuales, o bien una imposición de la

\footnotetext{
21 (...) la "irrenunciabilidad" moral de los derechos. "Inalienable" quiere decir estrictamente que "no puede ser renunciado". Y la idea de "no poder" en sentido moral no es sino la idea de "obligación moral de no hacer" o, si se prefiere acudir a otra técnica normativa, la idea de "inmunidad" respecto al propio estatus moral (Laporta, 1987, pág. 22)

22 En el caso del derecho a la vida no sería aplicable ya que de ese derecho es conditio sine qua non para ejercer la titularidad de cualquier otro derecho.

${ }^{23}$ Sobre la definición y diferenciación de persona y comunidades como sujetos de derechos o ser susceptibles de violaciones a Derechos Humanos se puede consultar la Corte Interamericana de Derechos Humanos. (2016). Opinión Consultiva. Oc-22/16. Recuperado de https://www.corteidh.or.cr/docs/opiniones/seriea_22_esp.pdf
} 
postura del antagonista más poderoso entre los grupos conflictuados. La eficacia de la Consulta Previa podría detonarse a partir de la articulación de un nuevo enfoque de esta basada en la deliberación de buena fe, que dé por sentado antes de iniciar el ejercicio democrático de la Consulta Previa que la alineación de intereses y la aceptación llana son ideales axiológicos aceptables de entrada para la construcción del consenso pero que finalmente el mismo incluirá la aceptación por las partes de diferencias que no pudieron ser aceptadas, pero sí negociadas.

La exigencia normativa de la aceptación por parte de los consultados representa un desacierto, en el entendido deliberativo democrático que por supuesto incluye como parte de los consensos el reconocimiento de las diferencias que se mantendrán y de las que se tendrá que generar un concierto de negociaciones que impliquen trueques de aceptación, concesiones rentables y compromisos políticos. En todo ello, los derechos humanos no son negociables, y representan la piedra de toque para cualificar los productos consensuados resultantes del ejercicio deliberativo de los antagonistas. Ahora bien, también hay que tener en consideración que cabe la posibilidad de explorar a la consulta previa como un ejercicio agonista ${ }^{24}$.

... La estrategia argumentativa de Mouffe es, como ya hemos señalado, proponer una distinción entre el antagonismo y el agonismo; la primera categoría representa una lucha entre enemigos, mientras que la segunda se da entre adversarios. Estos dos conceptos no son disímiles entre sí, sino complementarios y sirven para comprender una política democrática. De modo que, en el modelo agonístico democrático, los adversarios buscan la hegemonía, pero la confrontación se caracteriza por el respeto mutuo. El leitmotiv de Mouffe es que el antagonismo no sea eliminado, sino que sea sublimado y que, por medio de la crítica a la hegemonía dominante, se transformen las relaciones de poder. (Rojas, 2018, pág. 211)

\footnotetext{
${ }^{24}$ Introducir la categoría del «adversario» requiere hacer más compleja la noción de antagonismo y distinguir dos formas diferentes en las que puede surgir ese antagonismo, el antagonismo propiamente dicho y el agonismo. El antagonismo es una lucha entre enemigos, mientras que el agonismo es una lucha entre adversarios. Por consiguiente, podemos volver a formular nuestro problema diciendo que, visto desde la perspectiva del «pluralismo agonístico», el objetivo de la política democrática es transformar el antagonismo en agonismo. Esto requiere proporcionar canales a través de los cuales pueda darse cauce a la expresión de las pasiones colectivas en asuntos que, pese a permitir una posibilidad de identificación suficiente, no construyan al oponente como enemigo sino como adversario. (Mouffe 2014, pp. 115-116)
} 
Sin embargo, estas posibilidades podrían quedar para una segunda etapa o evolución de la CPLI en la que se cambiase la visión y el paradigma bajo el cual se ha desarrollado.

El carácter utópico de la aceptación lisa y llana que exige política y normativamente la Consulta Previa no ha permitido la recolección y reconocimiento de acuerdos valiosos que representan en sí mismo triunfos de los derechos humanos. La cerrazón normativa al todo o nada que representa la obligatoriedad jurisprudencial de la aceptación de los consultados impone posturas endurecidas de los intereses individuales que enarbolan los grupos, y, por otro lado, el uso del poder para franquear esas posturas por parte del Estado. El intercambio cultural que puede representar la Consulta Previa reestructurada a partir del ideal deliberativo conduciría a suavizar las exigencias de los intereses individuales y también a la moderación del uso del poder político que ante el requerimiento obligado de aceptación no se le ofrece más que la imposición del poder para la consecución programática del desarrollo económico público. Esto no significa que habrá una aprobación total y absoluta derivada de un consenso y su inmediata validez per se, sino que las posibilidades de haber minimizado los daños o maximizado los resultados positivos se dan con mayores posibilidades.

En los sistemas democráticos la participación de los gobernados en la creación de las políticas públicas y su forma de ejecución adquiere diferentes carices como en el caso de México con la elaboración del plan nacional de desarrollo ${ }^{25}$, en la consulta $\operatorname{popular}^{26}$ (Art.35 de la CPEUM), que expresa entre otros:

VIII. Votar en las consultas populares sobre temas de trascendencia nacional (...)

VIII. 3o. No podrán ser objeto de consulta popular la restricción de los derechos humanos reconocidos por esta Constitución; los principios consagrados en el artículo 40 de la misma; la materia electoral; los ingresos y gastos del Estado; la

\footnotetext{
${ }^{25}$ El Plan Nacional de Desarrollo se presenta en cumplimiento al Artículo 26 de la Constitución Política de los Estados Unidos Mexicanos y se elabora de acuerdo con lo establecido en la Ley de Planeación, tiene como finalidad establecer los objetivos nacionales, las estrategias y las prioridades que durante la Administración deberán regir la acción del gobierno, de tal forma que ésta tenga un rumbo y una dirección clara. Representa el compromiso que el Gobierno Federal establece con los ciudadanos y que permitirá, por lo tanto, la rendición de cuentas, que es condición indispensable para un buen gobierno. El Plan establece los objetivos y estrategias nacionales que serán la base para los programas sectoriales, especiales, institucionales y regionales que emanan de éste. (Secretaría de Finanzas del Estado de México, 2019)

${ }^{26}$ Mecanismo de participación ciudadana que sirve para ejercer el derecho constitucional para votar en torno a temas de trascendencia nacional de manera que su voluntad, vinculante conforme dicte la ley, pueda incidir en el debate y las decisiones que adoptan los órganos representativos del Estado. (Secretaría de Gobernación 2020)
} 
seguridad nacional y la organización, funcionamiento y disciplina de la Fuerza Armada permanente. La Suprema Corte de Justicia de la Nación resolverá, previo a la convocatoria que realice el Congreso de la Unión, sobre la constitucionalidad de la materia de la consulta... (Congreso de la Unión. 2020)

Y el concerniente a la Consulta Previa, libre, informada, de buena fe, culturalmente adecuada y a través de sus autoridades tradicionales, que tiene su fundamento base internacional en el 169 de la Organización Internacional del trabajo (OIT) y a nivel nacional en el artículo 2 de la Constitución Política de los Estados Unidos Mexicanos.

\section{Consideraciones finales}

La Consulta Previa representa una encrucijada entre el desarrollo nacional, el crecimiento económico o la aplicación de políticas masivas vs. la necesidad de conservación de las culturas de pueblos y comunidades originarias. La explotación forestal, petrolera, hidroeléctrica, minera, eólica, entre otros, se levantan como antagonistas de la conservación de las culturas tradicionales, su autonomía, territorialidad, autodeterminación, cosmogonía, formas de producción, utilización integral de recursos naturales y la reivindicación histórica tras la conquista.

Mientras las partes involucradas representadas por el Estado, empresas transnacionales y los pueblos y grupos indígenas, adversarios en palabras de Mouffe (2014, p. 115), conciban los unos la Consulta Previa como un escollo paralizante del desarrollo económico y los otros como un derecho para vetar proyectos públicos y privados, la Consulta Previa estará sujeta a las tensiones propias de un conflicto que se resuelve con el derrocamiento del otro antes que transformar al enemigo en adversario. (Mouffe, 2014, p. 115). El cambio de visión hacia una figura que lejos de exigir la aceptación o el convencimiento de los consultados, exalte las coincidencias, respete las negociaciones, y reconozca y acepte las diferencias irreconciliables, pudiera representar una mejor oportunidad para respetar los, en su momento, innegables derechos de unos y otros que se traslapan en el tiempo bajo argumentos válidos ambos de legalidad, justicia, desarrollo y bien común. ${ }^{27}$

\footnotetext{
27 No podemos olvidar que los derechos humanos están fundamentados, en general, desde una visión hegemónica del mundo, la cual sirve a los grandes intereses económicos y políticos, al saber y la fuerza de los que dominan el mundo. Esta fundamentación sostiene, entre otras cosas, la individualidad secante de las personas, el derecho a la acumulación de capitales, la igualdad formal de las personas ante la ley... Esta fundamentación en realidad es de los poderosos y los satisfechos, y está destinada a justificar una realidad que satisface a pocos y despoja a las mayorías de los más elementales medios para vivir como ser humano. (Llanos Martínez, 2014, p. 200)
} 
En términos prácticos, la Consulta Previa por la forma en que está estructurada jurídica y políticamente, representa un escenario de confrontación. La acotación de los intereses de las partes, al igual que la limitación del poder que pueden ejercerse recíprocamente para coaccionarse, representa una necesidad imperativa para la generación de un espacio de empaque democrático, negociación y deliberación. Hacer taxativa la aceptación y autorización de las comunidades y pueblos indígenas sobre las decisiones que pudieran afectarles lejos de representar un respaldo normativo sobresaliente representa un reto para el poder político y económico para la manipulación, coacción o simulación para la consecución de esa exigencia. Se replantea la necesidad de repensar el resultado de la Consulta Previa como un producto mixto en el que se articulen coincidencias, concesiones, compensaciones, intercambios, comercialización, y también, por supuesto, y de relevante carácter, el reconocimiento de diferencias infranqueables que habrá que abordar de manera singular; con la firmeza de convicción que un desacuerdo también representa un resultado respetable. ${ }^{28}$

Aunque la deliberación podría ser definida como una forma de comunicación que induce a la reflexión sobre las preferencias, valores e intereses en un desarrollo libre de coerciones en su ejercicio, a final de cuentas, los resultados sí son decisiones vinculantes para las partes que acordaron esta negociación. El consenso es general en cuanto a las condiciones que deben imperar en un proceso deliberativo democrático como lo es el tener la misma oportunidad de influir en el resultado, la igualdad de recursos, la protección de derechos básicos, y el respeto y consideración con el que deben tratarse en igualdad de circunstancias. Las partes deben escucharse mutuamente y darse las razones que consideren que las contrapartes pueden entender y aceptar.

El esfuerzo se centra en encontrar términos de cooperación justos entre personas libres e iguales y de buena fe. En las decisiones de corte democrático lo que distingue a los ejercicios deliberativos de los no deliberativos es la ausencia de la coerción; la intención de los participantes no es cambiar la conducta o comportamiento de los otros mediante la amenaza, la sanción o el uso de la fuerza.

\footnotetext{
28 Deliberative democracy has traditionally been defined in opposition to self-interest, to bargaining and negotiation, to voting, and to the use of power. Our assessment differs in two ways from the traditional one. First, we contend that self-interest, suitably constrained, ought to be part of the deliberation that eventuates in a democratic decision. Indeed, some forms of negotiation involving self-interest meet all of our criteria for ideal deliberation, in particular the criterion that in their ideal form deliberative methods eschew coercive power. We thus include such constrained self-interest and these forms of negotiation in our reformulation of the deliberative ideal, that is, the regulative standard to which real deliberations should aspire. Second, we argue for a complementary rather than antagonistic relation of deliberation to many democratic mechanisms that are not themselves deliberative. (Mansbridge, 2010)
} 
Una nueva propuesta de deliberación democrática incluye la convergencia de acuerdos comunicativos, acuerdos teóricamente incompletos, negociaciones integradoras y negociaciones distributivas totalmente cooperativas; que si bien todas derivan de intereses propios están exentos del elemento coercitivo en sus procesos. (Mansbridge, 2010, pp. 64-66) ¿Es posible llegar a esas condiciones iguales para todos?

El fundamento sociopolítico o de la praxis de la liberación es el aspecto sociohistórico, traducido en la lucha por recobrar la dignidad humana juridificando las necesidades. Este fundamento parte de la afirmación de que la realidad es dinámica y que el ser humano puede transformarlo con su poder creativo. El sujeto es reflexivo, pero también actúa es práxico y en realidad son los nuevos sujetos sociohistóricos que posibilitan la transformación del sistema, para dejar de ser sus víctimas, ejerciendo su derecho a generar derechos. El fundamento de la producción de vida significa el ideal de cambiar la sociedad para que todos accedan a condiciones justas de vida, que se logrará únicamente con la solidaridad. Aquí se considera al sujeto vivo, que requiere satisfacer sus necesidades físicas, vitales y se afirma que el sentido de la vida es vivirla y por ello, la transformación del sistema y la generación de una nueva institucionalidad deben tener como objetivo posibilitar la vida y evitar la muerte. Rosillo es consciente, sin embargo, de que no es posible pretender crear un sistema perfecto, es decir, un sistema que considere posible incluir todas las exigencias, satisfacer todas las necesidades de todos los seres humanos, sin que se generen nuevas víctimas y nuevas propuestas de transformación. (Llanos Martínez, 2014, pág. 201).

Resulta entonces prudente hablar del derecho humano a la Consulta Previa y a la autodeterminación como derechos colectivos sustentándolos en el carácter generacional de los derechos humanos y sobre la teoría garantista del derecho. ${ }^{29} \mathrm{La}$ autonomía individual está imbricada con la autonomía colectiva. Un ente autónomo requiere que su contexto social también lo sea. Las restricciones individuales harían nugatorios los derechos colectivos; y las restricciones a los colectivos harían

\footnotetext{
${ }^{29}$ Una segunda acepción se refiere al garantismo como teoría del derecho y crítica del derecho, es decir, una teoría de la validez y de la efectividad de las normas jurídicas que sirve de base para legitimar o deslegitimar las funciones que el derecho desempeña. Esta perspectiva es interna y estimula el espíritu crítico entre la validez de las normas y sus aplicaciones (Torres Ávila, 2015, pág. 6)
} 
inoperantes a los derechos individuales. Los seres humanos como agentes morales ${ }^{30}$ deben tener la capacidad de actuar legítimamente, y la conculcación de esos derechos disminuye esa capacidad, su autonomía y su libertad. Sin extravío se puede afirmar que el individuo para que sea positivamente autónomo debe serlo tanto en lo individual como en el contexto social en el que se encuentra inserto.

\section{Referencias Bibliográficas}

Avendaño, F.I. (2010). Un recorrido teórico a la territorialidad desde unos de sus ejes: El sentimiento de pertenencia y las identificaciones territoriales. Cuadernos Inter.c.a.mbio sobre Centroamérica y el Caribe 7 (8), 13-35. San José de Costa Rica.

Torres Ávila, T. (2017). La teoría del Garantismo: poder y constitución en el Estado contemporáneo. Revista de Derecho. Universidad del Norte. Barranquilla.

Bazant de Saldaña, M. (1999). 175 años de historia del Estado de México y perspectivas para el Tercer milenio. Hernández, C. G. Ed. El Colegio Mexiquense, A.C. doi:970-669-014-X.

Comisión Nacional de los Derechos Humanos. (2016). La consulta previa, libre, informada, de buena fe y culturalmente adecuada. Pueblos indígenas, derechos humanos y el papel de las empresas. (10). Comisión Nacional de los Derechos Humanos, Ciudad de México, México.

Comisión Nacional de los Derechos Humanos. (2018). Los principios de universalidad, interdependencia, indivisibilidad y progresividad de los derechos humanos. Comisión Nacional de los Derechos Humanos, Ciudad de México, México.

Congreso de la Unión. 2020. Constitución Politica de los Estados Unidos Mexicanos. Ciudad de México.

Corte Interamericana de Derechos Humanos. (2016). Opinión Consultiva. Oc-22/16. Recuperado de https://www.corteidh.or.cr/docs/opiniones/seriea_22_esp.pdf

\footnotetext{
${ }^{30}$ Es en este punto en donde pondríamos la función más característica de las normas jurídicas, prácticamente ligadas a la constitución del Estado, como una sistematización de las normas éticas y morales, orientada a resolver las contradicciones, a llenar las lagunas y a coordinar las normas yuxtapuestas (y también, es verdad, a generar un proceso infinito de "normas intercalares" específicamente jurídicas). Es en este proceso de sistematización en donde los deberes éticos o morales, en general, cobrarán la forma de derechos positivos estrictos garantizados por el Estado. Según esta concepción, decir, por ejemplo, que la política (o el derecho) "debe respetar la ética" no tiene el sentido de que la ética o la moral sea algo así como una regla más alta inspiradora de la política (como si el político o el jurista estuviese vigilado por el moralista, lo que es un último residuo de la subordinación del Estado a la Iglesia); pues no se trata de que se inspire por ella, sino, más bien, porque la ética y la moral son la materia sobre la que se basa la política y el derecho.
} 
Fondo Indígena. (s.f.). Libre determinación. Recuperado de http://www.fondoindigena.org/apc-aa-

files/documentos/monitoreo/Definiciones/Definicion\%20Campos/3_Libre\% 20Determinacion_def.pdf

Gálvez, Í. Á. (2do semestre de 2014). Universales, absolutos e inalienables: los derechos indestructibles. Revista de Humanidades de Valparaíso, (4).

García, C. B. (2009). ¿Multiculturalismo o interculturalidad? En Carrillo González D. (Ed.). Derecho, Interculturalidad y Resistencia Étnica, págs. 67-75, Bogotá.

González, M. d. (2007). Multiculturalismo y derechos humanos: limitar, tolerar o fomentar lo diferente. 3, 33-60. Recuperado de http://www.scielo.org.mx/scielo.php?script=sci_arttext\&pid=S1870$00632007000100002 \& \operatorname{lng}=$ es\&tlng=es.

Laporta, F. (1987). El Concepto de los Derechos Humanos. Doxa (4), 3. Recuperado el 26 de noviembre de 2020.

Llanos Martínez, A. (2014). Fundamentación de los Derechos Humanos desde América Latina de Alejandro Rosillo Martínez. REDHES Revista de Derechos Humanos y Estudios Sociales. (12), año VI, julio-diciembre. 199 - 202.

Luque, L. A. (Enero-Abril de 1993). Los límites de los derechos fundamentales. Revista del Centro de Estudios Constitucionales (14). Suprema Corte de Justicia de la Nación. Ciudad de México.

Mansbridge, Jane. (2010). The Place of Self-Interest and the Role of Power in Deliberative Democracy. The Journal of Political Philosophy, Wiley, 18(1), 64. doi:10.1111/j.1467-9760.2009.00344.x.

Mouffe, Chantal. (2014). Agonística. Pensar el mundo polkticamente. Buenos Aires: Fondo de Cultura Económica.

Muñoz, R. S. (2014). Un acercamiento al paradigma neoconstitucionalista. Publicaciones del consejo de la judicatura federal, Revista del Instituto de la Judicatura Federal $335 . \quad$ Recuperado de https://www.ijf.cjf.gob.mx/publicaciones/revista/Revistaesp2014/Rodrigo\% 20Salazar\%20Mu\%C3\%B1oz.pdf, Ciudad de México, México.

Nino, C. S. (2003). Filosofía y Derecho (Segunda ed.). (A. y. Depalma, Ed.) Astrea, Buenos Aires, Argentina.

Organización de las Naciones Unidas. (1945) Carta de las Naciones Unidas. Nueva York.

Organización de las Naciones Unidas. (1976). Pacto internacional de Derechos económicos, Sociales y Culturales. Nueva York.

Organización de las Naciones Unidas. (2007) Declaración de las Naciones Unidas sobre los derechos de los pueblos indígenas. Nueva York. 
Organización Internacional del Trabajo. (2014). Convenio 169 de la OIT sobre pueblos indígenas y tribales. Lima, Perú.

Pérez Luño, A. E. (1998). La universalidad de los derechos humanos. Sevilla, Sevilla, España: Universidad de Sevilla.

Rojas Huaynates, J. (2018). Chantal Mouffe. Agonística. Pensar el mundo políticamente. Ideas y $y$ Valores. 67(166), 211-214. https://dx.doi.org/10.15446/ideasyvalores.v67n166.68733

Rodríguez, R. B. (2010). Liberalismo y Comunitarismo: Un debate inacabado. STVDIVM. Revista de Humanidades. (16), 201-229.

Rosillo Martínez, A. (2013). Fundamentación de los Derechos Humanos desde América Latina. Editorial Ítaca. México.

Secretaría de Finanzas del Estado de México. (2019). Plan Nacional de Desarrollo. Recuperado de http://copladem.edomex.gob.mx/plan_nacional_de_desarrollo Secretaría de Gobernación. 2020. Consulta popular. Recuperado de http://sil.gobernacion.gob.mx/Glosario/definicionpop.php?ID=252)

Suprema Corte de Justicia de la Nación. 2002. Derechos de los indígenas. Los establecidos en las legislaciones locales en favor de ellos no fueron limitados por las reformas a la constitución federal en la materia, vigentes a partir del quince de agosto de dos mil uno. Ciudad de México.

Suprema Corte de Justicia de la Nación. 2010. Controversia constitucional 70/2009. Libre determinación y autonomía de los pueblos y las comunidades indígenas. Interpretación del artículo 2o., apartado a, fracciones iii y vii, de la Constitución Política de los Estados Unidos Mexicanos. Municipio de Santiago Yaveo, Choapam, Estado de Oaxaca.

Suprema Corte de Justicia de la Nación. (2013). Comunidades y pueblos indígenas. Todas las autoridades, en el ámbito de sus atribuciones, están obligadas a consultarlos, antes de adoptar cualquier acción o medida susceptible de afectar sus derechos e intereses. Semanario Judicial de la Federación y su Gaceta Libro XXIII, Agosto de 2013, Tomo 1; Materia(s): Constitucional; Tesis: 1a. CCXXXVI/2013 (10a.); Página: 736.

Wilhelmi, M. A. (Enero-Abril de 2009). La libre determinación y la autonomía de los pueblos indígenas. El caso de México. Boletín Mexicano de Derecho Comparado. Recuperado de https://revistas.juridicas.unam.mx/index.php/derechocomparado/article/view/4087/5262

Zayas, A. d. (2014). Apuntes prácticos para la apreciación de actividades y alegaciones relativas al ejercicio pacífico y democrático del derecho de libre determinación 
de los pueblos. Informe de experto independiente, Experto independiente, Geneva. Recuperado el 26 de noviembre de 2020.

Zolla, C., \& Zolla Márquez, E. (2004). ¿Qué se entiende por autonomía de los pueblos indígenas? En: Los pueblos indígenas de México. Universidad Nacional Autónoma de México Ed. Recuperado de http://www.nacionmulticultural.unam.mx/100preguntas/pregunta.php?num -pre $=35$ 